Standard open repair allowed the evacuation of the huge hematoma in the retroperitoneal space that was responsible for compartment syndrome leading to ischemic colitis.

Our experience is limited to one successful case, and no definitive conclusions can be reached concerning the choice of 1-stage surgery combining off-pump CABG and open repair of the ruptured aneurysm.

\section{References}

1. Mohr FW, Falk V, Autschbach R, Diegeler A, Schorn B, Weyland A, et al. One-stage surgery of coronary arteries and abdominal aorta in patients with impaired left ventricular function. Circulation. 1995;91: 379-85.
2. Hollier LH, Plate G, O’Brien PC, Kazmier FJ, Gloviczki P, Pairolero PC. et al. Late survival after abdominal aortic aneurysm repair: influence of coronary artery disease. J Vasc Surg. 1984;1: 290-9.

3. Campa JS, Greenhalgh RM, Powell JT. Elastin degradation in abdominal aortic aneurysms. Atherosclerosis. 1987;65:13-21.

4. Kameda Y, Taniguchi S, Kawata T, Tabayashi N, Kimura M. Minimally invasive direct coronary artery bypass combined with abdominal aortic aneurysm repair. Ann Thorac Surg. 1999;68: 1537-9.

5. Ascione R, Iannelli G, Spampinato N. Combined coronary artery and abdominal aortic surgery without cardiopulmonary bypass. Tex Heart Inst J. 2000;27:19-23.

6. Ohki T, Veith FJ. Endovascular grafts and other image-guided catheter-based adjuncts to improve the treatment of ruptured aortoiliac aneurysms. Ann Surg. 2000;232:466-79.

\title{
First experiences with the stable prostacyclin analog iloprost in the evaluation of heart transplant candidates with increased pulmonary vascular resistance
}

\author{
Armin Sablotzki, MD, ${ }^{a}$ Elke Czeslick, MD, ${ }^{\mathrm{b}}$ Ekkehard Gruenig, MD, ${ }^{\mathrm{c}}$ Ivar Friedrich, MD, ${ }^{\text {a }}$ Susann Schubert, MD, \\ Jochen Börgermann, MD, and Thomas Hentschel, MD, ${ }^{\mathrm{b}}$ Halle/Salle and Heidelberg, Germany
}

$\mathrm{A}$ $\mathrm{n}$ increased pulmonary vascular resistance (PVR) is described as a predictor of increased mortality after orthotopic heart transplantation. The measurement of pulmonary hemodynamics is a routine procedure in the assessment of potential transplant recipients because the information about the response to vasodilator therapy is of great interest for the postoperative management of right-heart failure. ${ }^{1}$

The therapeutic limitation of intravenous vasodilators is the systemic vasodilation and hypotension. Inhaled nitric oxide (NO) and prostacyclin $\left(\mathrm{PGI}_{2}\right)$ have been shown to act as selective pulmonary vasodilators without systemic effects in patients with primary and secondary pulmonary hypertension as well. ${ }^{2}$ Unfortunately, NO is a toxic molecule and requires specialized delivery systems and monitoring. Because of its short half-life, NO has to be administered continuously, and even brief interruptions can

\footnotetext{
From the Clinic of Cardiothoracic Surgery ${ }^{\mathrm{a}}$ and the Clinic of Anesthesiology and Intensive Care Medicine, ${ }^{\mathrm{b}}$ Martin-Luther-University Halle/Wittenberg, Halle/Salle, and the Clinic of Internal Medicine III, ${ }^{\mathrm{c}}$ University of Heidelberg, Germany.

Received for publication Feb 13, 2002; accepted for publication Sept 9, 2002.

Address for reprints: Armin Sablotzki, MD, Clinic of Cardiothoracic Surgery, Martin-Luther-University Halle/Wittenberg, Ernst-Grube-Str 40, 06120 Halle/Saale, Germany (E-mail: sablotzki@ aol.com).

J Thorac Cardiovasc Surg 2003;125:960-2

Copyright $\odot 2003$ by The American Association for Thoracic Surgery $0022-5223 / 2003 \$ 30.00+0$

doi: $10.1067 / \mathrm{mtc} .2003 .49$
}

cause a dangerous rebound of pulmonary hypertension. Inhaled $\mathrm{PGI}_{2}$ shows advantages because of the lack of toxic reactions but no improved effects on hemodynamics. ${ }^{2}$ Hoeper and colleagues ${ }^{3}$ described the use of aerosolized iloprost for severe pulmonary hypertension. Iloprost has a plasma half-life of 20 to 30 minutes and induces pulmonary vasodilation that persists for about 2 to 4 hours. It might also exert systemic circulatory effects because the molecule spills over into the systemic circulation. In patients with primary pulmonary hypertension, iloprost was more potent than inhaled NO.

Currently, there is no information about the use of iloprost in patients with secondary pulmonary hypertension caused by chronic cardiac failure. The aim of the present study was to compare the hemodynamic effects of inhaled NO and inhaled aerosolized iloprost in heart transplant candidates with increased pulmonary hypertension.

\section{Patients and Methods}

Twenty male patients (age, $52.8 \pm 5.8$ years) with increased PVR $\left(266.7 \pm 78\right.$ dynes $\left.\cdot \mathrm{s}^{-1} \cdot \mathrm{cm}^{-5}\right)$ scheduled for diagnostic rightheart catheterization were included after providing informed consent. The diagnoses were ischemic $(n=11)$ or dilated $(n=9)$ cardiomyopathy. Measurement of hemodynamics (mean arterial pressure, mean pulmonary artery pressure [MPAP], systemic vascular resistance [SVR], and pulmonary vascular resistance [PVR]) was performed by using a radial artery catheter and a pulmonary artery catheter. All parameters were determined at baseline and at the end of each evaluation period. Triplicate measurements were averaged for each reported cardiac output. 

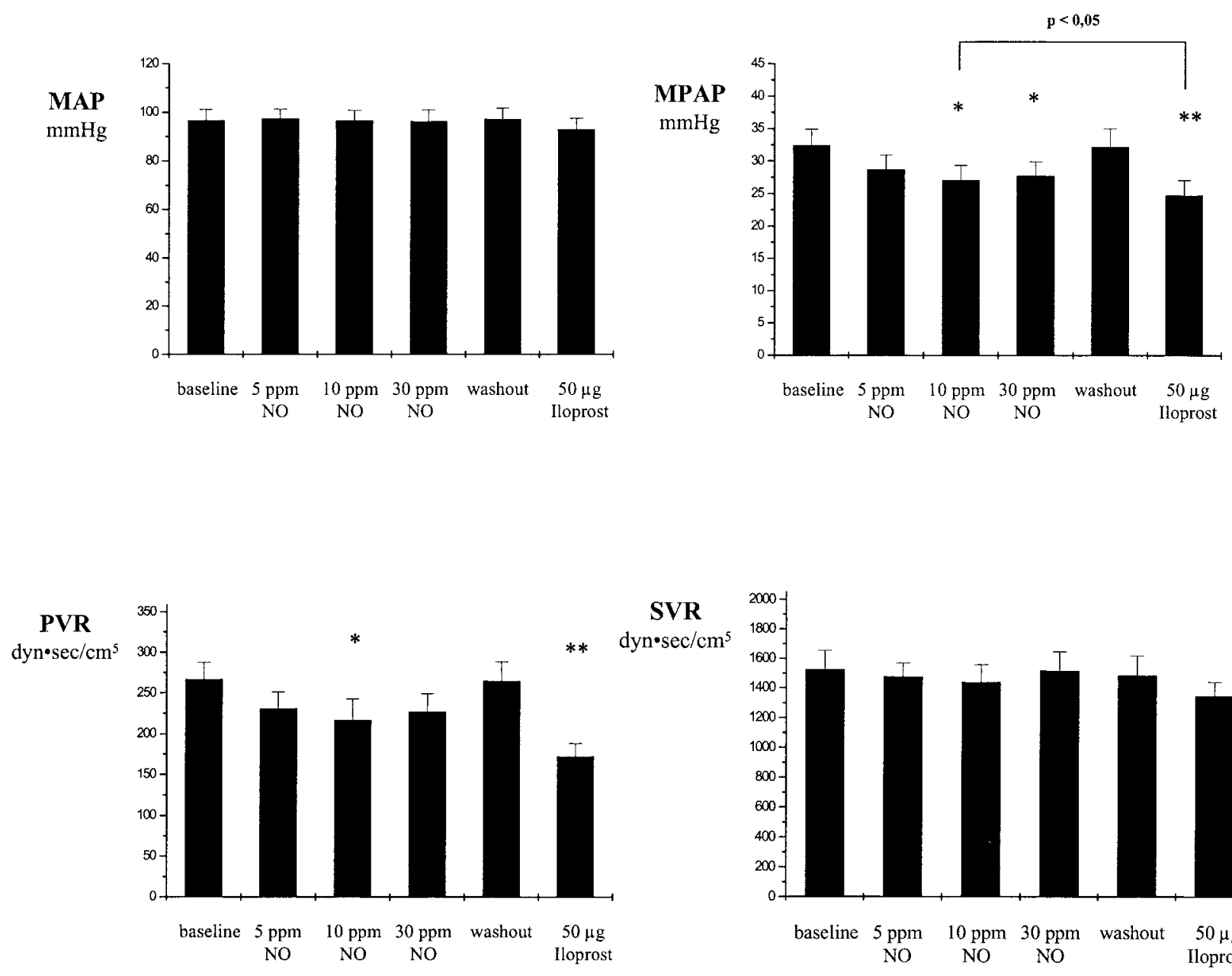

SVR

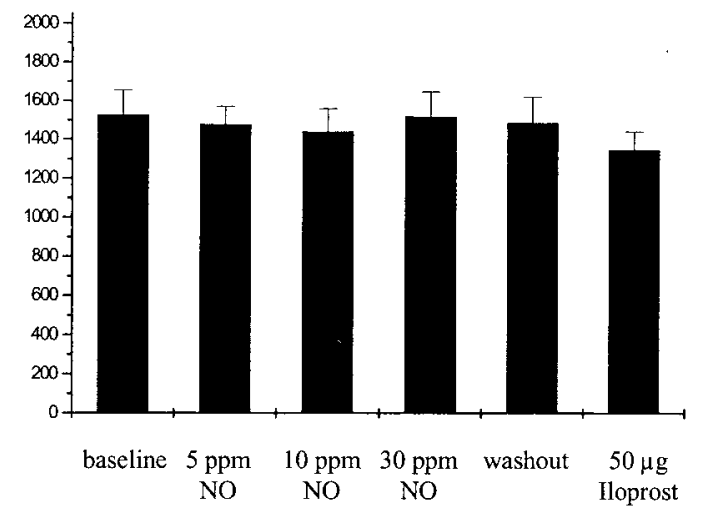

Figure 1. Influence of inhaled NO and iloprost on MPAP, mean arterial pressure (MAP), PVR, and SVR ( $=20)$. Data are expressed as means \pm SEM. ${ }^{*} P<.05,{ }^{* *} P<.01$ compared with baseline values.

During the whole study period, the patients were breathing medical air and oxygen in an inspiratory concentration of $25 \%$ through a tight-fitting face mask with a nonrebreathing circuit. NO was administered through a $\mathrm{T}$ piece in an inspiration-triggered modus to the inspiratory limb of the breathing device. The NO concentration was measured with a chemoluminometer.

After inhaling NO in concentrations of 5, 10, and $30 \mathrm{ppm}$, a complete evaluation of hemodynamics was performed. Thereafter, NO was discontinued, and after 20 minutes of washout, new basic hemodynamics were obtained before the inhalation of iloprost (Ilomedin; $50 \mu \mathrm{g}$ diluted in $3 \mathrm{~mL}$ of isotone saline solution) was started. Another hemodynamic measurement followed 5 minutes after the iloprost inhalation.

Results are expressed as mean values \pm SEM. Statistical analysis was made by using the nonparametric Friedman test, followed by the Wilcoxon-Wilcox test. The relationship between initial baseline PVR and MPAP levels and the effectiveness of both treatments was tested with the Mann-Whitney $U$ test. A $P$ value of less than .05 was considered to indicate statistical significance.

\section{Results}

All doses of NO and iloprost were well tolerated. There were no significant effects of both NO and iloprost on mean arterial blood pressure and SVR compared with baseline values. MPAP was reduced by 10 and $30 \mathrm{ppm} \mathrm{NO}$ and iloprost, respectively $(P<.05)$. Iloprost caused a greater decrease in MPAP compared with 10 ppm NO $(24.7 \pm 2.3$ vs $27.1 \pm 2.2 \mathrm{~mm} \mathrm{Hg}, P<.05)$ and $30 \mathrm{ppm}$ NO $(24.7 \pm 2.3$ vs $27.7 \pm 2.2 \mathrm{~mm} \mathrm{Hg}, P<.05)$. The PVR was significantly reduced by $10 \mathrm{ppm}$ NO and iloprost; the mean PVR values with iloprost $\left(172 \pm 16\right.$ dynes $\left.\cdot \mathrm{s}^{-1} \cdot \mathrm{cm}^{-5}\right)$ were lower than with $10 \mathrm{ppm} \mathrm{NO}\left(216 \pm 26.3\right.$ dynes $\left.\cdot \mathrm{s}^{-1} \cdot \mathrm{cm}^{-5}\right)$, but differences were not significant. Comparing the initial baseline levels of PVR and MPAP with the effectiveness of both therapies, we found no strong relationship (data not shown).

\section{Conclusions}

The use of $\mathrm{NO}$, aerosolized $\mathrm{PGI}_{2}$, or both for evaluation of heart transplant candidates with pulmonary hypertension has been described previously,,$^{2,4}$ although the use of iloprost in those patients has not been presented before. Haraldsson and associates ${ }^{4}$ de- 
scribed a selective dose-dependent decrease in PVR at an inhaled concentration of $10 \mu \mathrm{g}$ of $\mathrm{PGI}_{2}$ with no effects on systemic circulation, but the effects of $\mathrm{PGI}_{2}$ and $\mathrm{NO}$ in view of the induction of pulmonary vasodilation of heart transplant candidates were comparable. $^{2}$

In our study iloprost caused a significantly greater reduction in MPAP and a tendency toward a greater decrease of PVR than NO. This effect was not accompanied by a reduction of mean arterial pressure or SVR compared with baseline values or compared with values with NO. The main disadvantage of NO inhalation was an increase in MPAP and PVR in $4(28.6 \%)$ patients. This observation is nearly identical with the experience of Hoeper and coworkers, ${ }^{3}$ who reported an increase of MPAP in $23 \%$ and an increase of PVR in $31 \%$, respectively, while using comparable concentrations of NO. By contrast, none of our patients treated with iloprost had an increase in MPAP, PVR, or both.

Our study has several limitations. First, the chosen concentrations of NO might not have caused a maximum of vasodilation in all patients, but other studies have demonstrated that maximum effects on MPAP were achieved with NO concentrations of between 10 and $20 \mathrm{ppm}$ and that higher concentrations could not improve the effectiveness of NO. ${ }^{5}$ Furthermore, NO was given before iloprost, and although we ensured that the hemodynamics had returned to baseline before inhalation of iloprost, we can not completely exclude a priming effect of pretreatment with NO.

The results of our study show that inhaled aerosolized iloprost induces a reliable hemodynamic response in the evaluation of heart transplant candidates with increased PVR. Compared with the effects of inhaled NO, iloprost was more effective in reducing pulmonary artery pressure. Further advantages of iloprost inhalation are the lack of adverse reactions and an ease of administration. Because of these facts, we recommend iloprost as a routine screening drug for vascular reactivity, and we recommend further comparative studies to evaluate the place of iloprost in the management of perioperative pulmonary hypertension in cardiac transplantation in the near future.

\section{References}

1. Erickson K, Costanzo-Nordin M, O'Sullivan E, et al. Influence of preoperative transpulmonary gradient on late mortality after orthotopic heart transplantation. J Heart Lung Transplant. 1990;9:52637.

2. Haraldsson A, Kieler-Jensen N, Nathorst-Westfelt U, et al. Comparison of inhaled nitric oxide and inhaled aerosolized prostacyclin in the evaluation of heart transplant candidates with elevated pulmonary vascular resistance. Chest. 1998;114:780-6.

3. Hoeper MM, Olschewski H, Ghofrani HA, et al. A comparison of the acute hemodynamic effects of inhaled nitric oxide and aerosolized iloprost in primary pulmonary hypertension. J Am Coll Cardiol. 2000; 35: 176-182.

4. Haraldsson A, Kieler-Jensen N, Ricksten SE. Inhaled prostacyclin for treatment of pulmonary hypertension after cardiac surgery or heart transplantation: a pharmacodynamic study. J Cardiothorac Vasc Anesth. 1996;10:864-8.

5. Sitbon O, Brenot F, Denjean A, et al. Inhaled nitric oxide as a screening vasodilator agent in primary pulmonary hypertension: a dose-response study and comparison with prostacyclin. Am J Respir Crit Care Med. 1995;151:384-9. 